\title{
Are complications of endoscopic sphincterotomy age related?
}

\author{
G T Deans, P Sedman, D F Martin, C M S Royston, C K Leow, W E G Thomas, \\ W A Brough
}

Stockport Unit for Minimally Invasive Therapy, Stepping Hill Hospital, Stockport SK2 7JE, UK

G T Deans

W A Brough

Hull Royal Infirmary, Hull, UK

P Sedman

C M S Royston

South Manchester University Hospital, Manchester, UK

D F Martin

Royal Hallamshire Hospital, Sheffield, UK C K Leow

W E G Thomas

Correspondence to: Mr Deans.

Accepted for publication 2 June 1997

\begin{abstract}
Background-Endoscopic retrograde cholangiopancreatography sphincterotomy is increasingly performed in younger patients undergoing laparoscopic cholecystectomy. However, the safety of endoscopic sphincterotomy in this age group, relative to that in older patients, is unknown.
\end{abstract}

Aim-To determine whether the development of short term complications following endoscopic sphincterotomy is age related.

Patients and methods-A prospective multicentre audit of 958 patients (mean age 73 , range $14-97$, years) undergoing a total of 1000 endoscopic sphincterotomies. Results-Two deaths occurred, both from postsphincterotomy acute pancreatitis. Postprocedural complications developed in 24 patients: pancreatitis in 10, ascending cholangitis in seven, bleeding in four, and retroperitoneal perforation in three. There were six complications (five cases of pancreatitis and one bleed; $2.2 \%$ ) and no deaths in the $281(29.3 \%)$ patients aged under 65 years. In comparison, $18(2.6 \%)$ of the 677 patients aged over 65 years developed a complication (cholangitis in seven, pancreatitis in five, bleeding in three, and perforation in three). Patients under $35,45,55$, and 65 years were not at significantly increased risk of complication than those over these ages (relative risk for those under compared with those over 65 years $0.83,95 \%$ confidence intervals $0.41-1.67, \mathrm{p}=0.74$ ).

Conclusion-Short term complications following endoscopic sphincterotomy are not related to age. Younger patients undergoing laparoscopic cholecystectomy need not be denied endoscopic sphincterotomy for fear that the risks are greater than if they undergo surgical exploration of the common bile duct.

(Gut 1997; 41: 545-548)

Keywords: Endoscopic retrograde cholangiopancreatography; laparoscopic cholecystectomy; aging
Endoscopic sphincterotomy is currently the procedure of choice for the management of retained bile duct stones following cholecystectomy and is used increasingly to treat acute gallstone pancreatitis and high-risk patients with choledocholithiasis in the presence of an intact gall bladder. ${ }^{12}$ The management of bile duct stones in the era of laparoscopic cholecystectomy has further expanded the need for endoscopic sphincterotomy. ${ }^{3}$ Laparoscopic intraoperative cholangiography followed by conversion to open bile duct exploration considerably prolongs the procedure and denies the patient the benefits of laparoscopic cholecystectomy. ${ }^{4}$ Laparoscopic bile duct exploration is a well established technique ${ }^{5}$ but the time and skill required are likely to prevent it becoming universally available to patients. Many clinicians therefore use preoperative endoscopic retrograde cholangiopancreatography (ERCP) and sphincterotomy to remove bile duct stones and thereby increase the efficacy of the laparoscopic procedure and reduce the rate of conversion to open cholecystectomy. ${ }^{34}$ As a result, an increasing number of young patients may in future be referred for endoscopic sphincterotomy.

The morbidity and mortality of exploration of the bile ducts increases with age so that in the elderly endoscopic sphincterotomy is associated with fewer complications than surgery. ${ }^{67}$ Some surgeons are reluctant to perform endoscopic sphincterotomy in younger patients, believing that the $1 \%$ mortality of this technique is unacceptable relative to that of an operative approach. However, this figure reflects the mortality of endoscopic sphincterotomy in all age groups, there being no data on whether younger patients are at greater risk of complication following this procedure than older patients. Such a study is necessary, given the likely increase in demand for endoscopic sphincterotomy in patients undergoing laparoscopic cholecystectomy. We have therefore performed a multicentre, prospective audit of patients undergoing endoscopic sphincterotomy for gallstone related conditions to determine whether the incidence of postprocedural complications is related to age. 


\section{Patients and Methods}

A prospective study was established to assess the relation between complications following endoscopic sphincterotomy and the age of the patient. The study consisted of 1000 endoscopic sphincterotomies (both pre- and postoperative) performed for gallstones or their complications at four hospitals in the United Kingdom between January 1990 and June 1995. Entry criteria included all patients undergoing sphincterotomy for bile duct stones, as indicated by a history of jaundice or cholangitis, dilated bile ducts on ultrasound, abnormal liver function tests, or acute gallstone pancreatitis. Patients undergoing sphincterotomy for the management of tumours, non-specific abdominal pain or papillary stenosis unrelated to gallstones were excluded.

The preparation for the procedure was identical in all centres. All procedures were performed by experienced endoscopists using routine techniques and contrast media which was injected under low pressure. Instrumentation was minimised and a wire-guided sphincterotome used whenever possible. Those in whom large or multiple stones could not be removed with a basket or mechanical lithotriptor had an endoprosthesis inserted to maintain biliary drainage. Patients were observed in hospital for 24 hours postprocedure and serial serum amylase concentrations were measured in any patient with significant abdominal pain. Any problem that occurred following discharge was noted by the patient who was subsequently contacted by telephone. All procedure related morbidity and mortality within 30 days of sphincterotomy were then recorded, patients with inadequate follow up being excluded from the study. A comparison of the significance (Fisher's exact test, $\chi^{2}$ test with Yates's correction) and relative risk of developing a complication in those under and over $35,45,55$, and 65 years of age were determined.

\section{Results}

The 1000 endoscopic sphincterotomies were performed on 958 patients (635 women and 323 men). Median age was 73 years (range 14-97). Indications for ERCP leading to sphincterotomy were jaundice/cholangitis (617 procedures), sonogram suggesting bile duct stones (146 procedures), acute pancreatitis (135 procedures), abnormal liver function tests (59 procedures), and postcholecystectomy symptoms (43 procedures).

There were two deaths (mortality $0.21 \%$ ), both from postsphincterotomy acute pancreatitis, in patients aged 74 and 76 years. There were 24 postprocedural complications, no patient experiencing more than one complication. Pancreatitis (diagnosed by a serial rise in serum amylase concentrations) was the most common complication, occurring after 10 procedures $(1 \%)$, and accounting for the two deaths. Five of those who developed pancreatitis were under 65 years of age $(26,45,46,48$, and 49 years). Ascending cholangitis developed in seven patients $(0.8 \%)$, all over 65 years old, and was related to incomplete clearance of stones. Four patients $(0.4 \%)$, aged $46,79,80$,
TABLE 1 Mortality and morbidity of endoscopic sphincterotomy in relation to age

\begin{tabular}{|c|c|c|c|}
\hline Age (y) & $\begin{array}{l}\text { Number of } \\
\text { patients }\end{array}$ & Mortality & $\begin{array}{l}\text { Complications (number } \\
\text { of patients) }\end{array}$ \\
\hline$<35$ & 35 & 0 & Pancreatitis (1) \\
\hline $35-44$ & 33 & 0 & None \\
\hline $45-54$ & 64 & 0 & $\begin{array}{l}\text { Pancreatitis (4) } \\
\text { Bleeding (1) }\end{array}$ \\
\hline $55-64$ & 149 & 0 & None \\
\hline$>65$ & 677 & 2 & $\begin{array}{l}\text { Cholangitis (7) } \\
\text { Pancreatitis (5) } \\
\text { Bleeding (3) } \\
\text { Perforation (3) }\end{array}$ \\
\hline
\end{tabular}

TABLE 2 The relative risk, 95\% confidence intervals and significance of developing complications in those under, relative to over, a given age

\begin{tabular}{llll}
\hline Age $(y)$ & $\begin{array}{l}\text { Relative risk } \\
\text { (under versus } \\
\text { over that age) }\end{array}$ & $\begin{array}{l}\text { 95\% } \\
\text { Confidence } \\
\text { intervals }\end{array}$ & p Value \\
\hline$<35$ & 2.6 & $0.65-11.2$ & 0.18 \\
$<45$ & 1.15 & $0.3-4.42$ & 0.70 \\
$<55$ & 1.73 & $0.85-3.53$ & 0.14 \\
$<65$ & 0.83 & $0.41-1.67$ & 0.74
\end{tabular}

and 83 years developed bleeding requiring transfusion after sphincterotomy. Two (aged 46 and 80 years) required surgical intervention. Three patients $(0.3 \%)$, aged 66,70 , and 73 years, had radiological evidence of retroperitoneal perforation. Each resolved spontaneously with conservative management.

There was one complication (pancreatitis) among the 68 patients under 45 years of age (table 1). Six complications (five cases of pancreatitis and one bleed) occurred in the 132 $(13.2 \%)$ patients aged under 55 years with no further complication arising in the 149 patients aged 55-64 years. Consequently, there were six complications $(2.2 \%)$ and no deaths in the 281 $(29.3 \%)$ patients aged under 65 years. In comparison, 18 of the 677 patients aged over 65 $(2.6 \%)$ years developed complications (cholangitis in seven, pancreatitis in five, bleeding in three, and perforation in three). The two deaths occurred in this group. Patients under 65 years of age were not at increased risk of developing complications compared with those over 65 (relative risk $0.83,95 \%$ confidence intervals $0.41-1.67, \mathrm{p}=0.74$ ). Similarly, the risk of complication was not greater in those under and over 35, 45 and 55 years of age (table 2).

\section{Discussion}

Young patients with bile duct stones may be advised to undergo surgical exploration in the belief that this is associated with fewer complications than endoscopic sphincterotomy. This belief has arisen because the quoted mortality of endoscopic sphincterotomy is around $1 \%$, whereas the mortality of bile duct exploration increases with age only exceeding $1 \%$ over the age of 60 years. However, mortality figures for endoscopic sphincterotomy represent global mortality and encompass all age groups. In the past, only selected young patients considered unfit for surgery underwent endoscopic sphincterotomy, inevitably influencing results and attitudes. It is not known whether the mortality and morbidity of endoscopic 
sphincterotomy vary with age or that young patients are at greater risk of complications following sphincterotomy than bile duct exploration.

Prospective studies comparing preoperative endoscopic sphincterotomy with bile duct exploration reveal that the ability to clear stones from the bile duct, morbidity, mortality, hospital stay, length of operation, and hospital cost show no difference in outcome between young and elderly patients. ${ }^{7-9}$ Mortality of exploration of the bile ducts increases with age so that by 60 years mortality is around $1 \%$ and continues to increase thereafter. ${ }^{611}{ }^{12}$

The mortality rate in this study $(0.2 \%)$ compares favourably with that of other series of endoscopic sphincterotomy $(0-5 \%){ }^{1}{ }^{13} 15$ In one study of 500 patients after sphincterotomy, immediate and 30-day mortality were $1 \%$ and $3 \%$, while a retrospective multicentre study of 10000 patients undergoing sphincterotomy revealed a $0.6 \%$ mortality. ${ }^{16}{ }^{17}$ In the present series two deaths occurred in patients aged 74 and 76 years. This study does not support the belief that young patients undergoing endoscopic sphincterotomy have a mortality of $1 \%$ or greater. ln contrast, this series suggests that, for a given age, endoscopic sphincterotomy performed by experienced clinicians may even be associated with a reduced mortality relative to exploration of the bile duct.

Evidence suggesting that young patients experience greater morbidity after endoscopic sphincterotomy is also lacking. Morbidity can be expected in $5-15 \%$ of patients after endoscopic sphincterotomy, most series reporting significant complications in around $5 \% .^{13131617}$ The commonest complication in the present series was procedure related pancreatitis, which occurred in $1 \%$ of patients. These results compare favourably with other reports suggesting that acute pancreatitis develops in around $2.5 \%$ of patients following sphincterotomy. ${ }^{18}$ In this series there was no correlation between age and procedure induced pancreatitis. It therefore seems likely that pancreatitis following sphincterotomy is more related to other factors such as trauma to the pancreatic duct orifice rather than the age of the patient. ${ }^{19}$

Bleeding following sphincterotomy is reported in around $5 \%$ of cases and is associated with considerable mortality. ${ }^{15}{ }^{20}$ The low incidence of bleeding in this series $(0.36 \%)$ may be related to limiting the size of the sphincterotomy, a practice common to all the endoscopists. Two patients in our series required surgical intervention for bleeding, two other cases settling spontaneously without the need for endoscopic or other active intervention.

In this series all cases of ascending cholangitis following sphincterotomy occurred only in elderly patients. Persistent or recurrent sepsis reportedly occurs after $2.5 \%$ of sphincterotomies. ${ }^{20}$ The relatively low number of patients with persistent sepsis in the present series $(0.8 \%)$, without mortality, may be related to the use of a biliary endoprosthesis in cases in which clearance of the bile duct was considered incomplete. Asymptomatic retro- peritoneal perforation is recognised to complicate therapeutic ERCP even when sphincterotomy is not performed. ${ }^{21}$ This study suggests that younger patients are not at increased risk of this complication which, however, may be successfully treated conservatively. Even patients who develop persistent pain, fever and leucocytosis can be managed non-operatively, progress being monitored by computed tomography if necessary.

Another major concern of the performance of endoscopic sphincterotomy in young patients is the potential for long term complications. Between $75 \%$ and $90 \%$ of all patients undergoing endoscopic sphincterotomy will remain asymptomatic up to 15 years after the procedure. ${ }^{19}$ Recurrence of biliary stones occurs in $10 \%$ of patients while reintervention for stenosis may be required in around $3 \% .^{14}{ }^{17}{ }^{19}$ Recurrent stones can be successfully treated by repeat sphincterotomy in $90 \%$ of cases. Although this study did not assess long term complications, serious consequences of endoscopic sphincterotomy are sufficiently uncommon to make significant long term problems in young patients unlikely.

Another concern relates to the long term risks of sphincter destruction. However, there is no evidence that surgical sphincteroplasty has any long term risk other than that associated with stenosis. Moreover, there is evidence that even with endoscopic sphincterotomy large enough to allow duct clearance, sphincter function is preserved in $50 \%$ of patients. $^{22}$

Only one third of patients undergoing ERCP prior to laparoscopic cholecystectomy require sphincterotomy for bile duct stones. ${ }^{23}$ In such patients, this combined therapeutic approach should offer an effective, time-saving option compared with open cholecystectomy and common bile duct exploration. ${ }^{3} 89$ Our results suggest that neither the morbidity nor mortality of endoscopic sphincterotomy is age related. Younger patients should therefore not be denied the benefits of laparoscopic cholecystectomy after preliminary endoscopic sphincterotomy for fear that the risks are greater than if they undergo surgical exploration of the bile duct.

\footnotetext{
1 Kullman E, Borch K, Dahlin LG, Liedberg G. Long term follow up of patients with gallbladder in situ after endoscopic sphincterotomy for choledocholithiasis. Eur 7 Surg 1991; 157: 131-5.

2 Neoptolemos JP, London N, Slater ND, et al. A prospective study of ERCP and endoscopic sphincterotomy in the diagnosis and treatment of gallstone acute pancreatitis. diagnosis and treatment of g

3 Neuhaus H, Feussner H, Ungeheuer A, Hoffmann W, Siewert JR, Classen $M$. Prospective evaluation of the use of endoscopic retrograde cholangiography prior to laparoscopic cholecystectomy. Endoscopy 1992; 24: 745-9.

4 Reddick EJ, Olsen D, Alexander W, Bailey A, Baird D, Price N, Pruitt R. Laparoscopic laser cholecystectomy and choledocholithiasis. Surg Endosc 1990; 4: 133-4.

5 Phillips EH, Carroll BJ, Pearlstein AR, Daykhovsky L, Falas MJ. Laparoscopic choledochoscopy and extraction of common bile duct stones. World F Surg 1993; 17: 22-8

6 Bredesen J, Jorgensen T, Andersen TF, Bronnum Hansen $\mathrm{H}$, Roepstorff C, et al. Early postoperative mortality following cholecystectomy in the entire female population of Denmark, 1977-1981. World f Surg 1992; 16: 530-5.

7 Girard RM, Morin M. Open cholecystectomy: its morbidity Girard RM, Morin M. Open cholecystectomy: its morbidity
and mortality as a reference standard. Can $\mathcal{f}$ Surg 1993; 36: and 80 .

8 Stain SC, Cohen Hi Tsuishoysha M, Donovan AJ. Choledocholithiasis. Endoscopic sphincterotomy or common bile duct exploration. Ann Surg 1991; 213: 627-33.
} 
9 Stiegmann GV, Goff JS, Mansour A, Pearlman N, Reveille RM, Norton L. Precholecystectomy endoscopic cholangiography and stone removal is not superior to cholecystectomy, cholangiography, and common duct exploration. $A m$ 7 Surg 1992; 163: 227-30.

10 Ransohoff DF, Gracie WA. Management of patients with symptomatic gallstones: a quantitative analysis. $A m \mathcal{F} \mathrm{Med}$ 1990; 88: 154-60.

11 Kocher M, Herzog U, Schuppisser JP, Ackermann C, Tondelli $\mathrm{P}$. What is the contribution of surgery in cholelithiasis today? Helv Chir Acta 1992; 58: 969-76.

12 Glattli A, Baer HU, Schirp B, Gilg M, Gertsch P, Blumgart LH. Is surgical bile duct revision in choledocholithiasis still indicated? Helv Chir Acta 1992; 58: 987-92.

13 Wong PY, Lane MR, Hamilton I. Endoscopic management of bile duct stones at Auckland Hospital in 1988 and 1989. NZ Med F 1991; 104: 403-5.

14 Tanaka M, Ogawa Y, Naritomi G, Yokohata K, Kimura H. Clinical significance of endoscopic sphincterotomy compared with surgical common bile duct exploration and surgical sphincterotomy. Nippon Geka Gakkai Zasshi 1992; 93. gical sphinct

15 Csaky G, Papp L, Berecz J, Juhasz L, Orosz P. Surgical treatment of gallbladder diseases in patients over 70 years of age. Orv Hetil 1993; 134: 2195-9.
16 Seifert E, Schulte F, Chalybaus C. Ouo vadis endoscopic sphincterotomy? Z Gastroenterol 1989; 27: 77-82.

7 Ginestal Cruz A, Grima N, Correia AP, Duarte V, Correia JP. Endoscopic sphincterotomy in choledocholithiasis: analysis of an experience of 530 interventions. Acta Med Port 1990; 3: 133-40.

18 Shinagawa N, Mashita K, Yura J. The operative risk factors of cholelithiasis in the elderly. Surg Today 1992; 22: 29-34.

19 Hansell DT, Millar MA, Murray Wit, Gray GR, Gillespie G. Endoscopic sphincterotomy for bile duct stones in patients with intact gallbladders. Br f Surg 1989; 76: 856-8.

20 Himal HS, Lindsay T. Ascending cholangitis: surgery versus endoscopic or percutaneous drainage. Surgery 1990; 108: 629-33.

21 Martin DF, Tweedle DE. Retroperitoneal perforation during ERCP and endoscopic sphincterotomy: causes, clinical features and management. Endoscopy 1990; 22: $174-5$.

22 Lang I, Martin DF. Gallbladder function after endoscopic sphincterotomy: a dynamic ultrasound assessment. $\mathrm{Br} \mathcal{F}$ Rphincterotomy: a dyna 1993 ; 66: 585-7.

23 Surick B, Washington M, Ghazi A. Endoscopic retrograde cholangiopancreatography in conjunction with laparoscopic cholecystectomy. Surg Endosc 1993; 7: 388-92. 